Received: 2021/01/29, Revised: 2021/03/23, Accepted: 2021/03/30, Published: 2021/03/31 @2021 Matthew Sharp et al.; Licence Physical Activity and Nutrition. This is an open access article distributed under the terms of the creative commons attribution license (https:/l creativecommons.org/licenses/by-nc/2.0/), which permits unrestricted use, distribution, and reproduction in any medium, provided the orginal work is properly cited.

${ }^{*}$ Corresponding author : Matthew Sharp

Research Division, Applied Science and Performance Institute; Tampa, Florida, USA 33607.

Tel: +813-673-8888

Fax: +813-354-4891

E-mail: msharp@theaspicom

@2021 The Korean Society for Exercise Nutrition
[Purpose] This study investigated the effects of marine phytoplankton supplementation (Oceanix ${ }^{\circledR}$, Tetraselmis chuii) on 1) maximal isometric strength and immune function in healthy humans following a oneweek high-intensity resistance-training program and 2) the proinflammatory cytokine response to exercise in a rat model.

[Methods] In the human trial, 22 healthy male and female participants were randomly divided into marine phytoplankton and placebo groups. Following baseline testing, participants underwent a 14-day supplement loading phase before completing five consecutive days of intense resistance training. In the rat model, rats were randomly divided into four groups ( $n=7$ per condition): (i) control, (ii) exercise, (iii) exercise + marine phytoplankton (2.55 mg/kg/day), or (iv) exercise + marine phytoplankton $(5.1 \mathrm{mg} / \mathrm{kg} / \mathrm{day})$. Rats in the exercising groups performed treadmill exercise 5 days per week for 6 weeks.

[Results] In the human model, marine phytoplankton prevented significant declines in the isometric peak rate of force development compared to placebo. Additionally, salivary immunoglobulin A concentration was significantly lower following the resistance training protocol in the placebo group but not in the marine phytoplankton group. Marine phytoplankton in exercising rats decreased intramuscular levels and serum concentrations of tumor necrosis factor-alpha (TNF- $\alpha$ ) and interleukin-1 beta (IL-1 $\beta$ ) and intramuscular concentrations of malondialdehyde.

[Conclusion] Marine phytoplankton prevented decrements in indices of functional exercise recovery and immune function. Mechanistically, these outcomes could be prompted by modulating the oxidative stress and proinflammatory cytokine response to exercise.

[Key words] cytokines, exercise recovery, immune function, antioxidant, muscle strength, immunoglobulin, oxidative stress

\section{Marine phytoplankton improves recovery and sustains immune function in humans and lowers proinflammatory immunoregulatory cytokines in a rat model}

\author{
Matthew Sharp ${ }^{1^{*}} /$ Jacob Wilson ${ }^{1}$ / Matthew Stefan ${ }^{1} /$ \\ Raad Gheith ${ }^{1}$ / Ryan Lowery ${ }^{1}$ / Charlie Ottinger ${ }^{1}$ / \\ Dallen Reber ${ }^{1}$ / Cemal Orhan² / Nurhan Sahin² / \\ Mehmet Tuzcu ${ }^{3}$ / Shane Durkee ${ }^{4}$ / Zainulabedin Saiyed ${ }^{4}$ / \\ Kazim Sahin ${ }^{2}$ \\ 1. Research Division Applied Science and Performance Institute, Florida, USA \\ 2. Department of Animal Nutrition, Firat University, Elazig, Turkey \\ 3. Department of Biology, Firat University, Elazig, Turkey \\ 4. Lonza Consumer Health Inc. Greenwood, South Carolina, USA
}

\section{INTRODUCTION}

Muscle damage caused by intense exercise disrupts tissue homeostatic balance and causes a series of biological events, such as inflammatory responses, to initiate skeletal muscle repair ${ }^{1-3}$. One particular inflammatory response of interest is that of cytokines ${ }^{4}$. "Cytokine" is an umbrella term that refers to a group of glycoproteins produced by the immune system to facilitate communication within immune cells and between immune and non-immune cells ${ }^{4}$. The production of proinflammatory cytokines, such as interleukin-1 beta (IL-1 $\beta$ ) and tumor necrosis factor-alpha (TNF- $\alpha)^{5}$, is accelerated in response to inflammatory stimuli (e.g., muscle damage), and this response can be temporary or extended ${ }^{4}$. Cytokines are essential to the damage, repair, and remodeling processes involved in muscle tissue in response to exercise $\mathrm{e}^{2,4}$

Additionally, intramuscular inflammation can be significantly attributed to mitochondrial uncoupling and subsequent induction of reactive oxygen species (ROS) ${ }^{6}$, which is vastly increased during strenuous exercise $^{7}$. Exposure to excessive free radicals can impair immune function ${ }^{8}$ and provoke performance decrements ${ }^{9,10}$. Moreover, ROS can amplify the proinflammatory cytokine response to exercise ${ }^{11,12}$, which may be deleterious and lead to maladaptation. The increase in ROS levels and subsequent elevation of proinflammatory cytokines following exercise have a temporary depressive effect on immune function, which could make individuals more susceptible to infection ${ }^{13}$.

Salivary immunoglobulin A ( $\operatorname{IgA})$ is considered the first line of defense, as sIgA binds to and opsonizes pathogenic organisms, including respiratory viruses ${ }^{14}$. As such, sIgA concentration has been examined as a biomarker to evaluate the immune status of athletes. Long durations of intense exercise, both acutely and chronically, decrease sIgA levels and are associated with increased respiratory infection symptoms ${ }^{15}$. For example, sIgA levels decrease in athletes undergoing overreaching 
programs and/or experiencing upper respiratory infections 16-18. Thus, regulating pro-oxidative and proinflammatory responses could be a viable method of immunomodulation for exercise recovery.

An individual's nutritional status has been shown to robustly influence antioxidant status, immune function, and recovery ability ${ }^{19}$. As a result, a fair amount of attention has been given to antioxidant supplements for exercise recovery, which is largely due to their capacity to enhance endogenous support in diminishing oxidative damage by neutralizing $\operatorname{ROS}^{20,21}$. The majority of studies investigating the impact of antioxidant supplementation on exercise have reported that antioxidants can reduce oxidative stress ${ }^{22}$; however, the physiological implications of this effect are not well known. Furthermore, strong evidence supporting antioxidant supplementation as a protectant against muscle damage is incomplete, as most investigations do not consider oxidative stress markers and proinflammatory cytokines in conjunction with functional indices of muscle damage, such as loss of muscle force and power ${ }^{22,23}$.

Scientists have isolated a unique marine phytoplankton (MP), the microalgae Tetraselmis chuii (Oceanix ${ }^{\circledR}$, Lonza Consumer Health Inc., Greenwood, SC, USA.). This microalgae contains highly active antioxidant enzymes, particularly superoxide dismutase (SOD), which catalyzes the conversion of superoxide into ordinary molecular oxygen, thereby protecting cells from oxidative damage ${ }^{24}$. Tetraselmis chuii was also found to upregulate glutathione peroxidase and catalase enzymes in human skeletal muscle myoblasts in vitro ${ }^{24}$. Antioxidants have been shown to aid in exercise recovery ${ }^{25-28}$. Mechanistic cell culture models have demonstrated a reduction in oxidative stress in response to Tetraselmis chuii exposure ${ }^{24}$, which prompted our study design to investigate the link between oxidative stress and immune-related responses.

Thus, the current study examined the effects of microalgae Tetraselmis chuii supplementation on functional indices of muscle damage and immune function in humans following a short-term, muscle-damaging bout of anaerobic exercise. This was followed by a mechanistic rat trial to determine whether this nutritional intervention affected recovery through the production of proinflammatory immunoregulatory cytokines. We hypothesized that Tetraselmis chuii supplementation can attenuate decrements in muscle and immune function in humans and mitigate proinflammatory cytokine production and oxidative stress in exercising rats.

\section{METHODS}

\section{Human Trial}

Study Participants

Male and female participants were recruited by word of mouth, email contact, and direct website inquiries from online advertisements. Participants were excluded from the study if they had a body mass index $(\mathrm{BMI}) \geq 30 \mathrm{~kg} / \mathrm{m}^{2}$; had allergies to fish, shellfish, algae, or seaweed had any cardio- vascular, metabolic, or endocrine disease; had undergone surgery that affects digestion and absorption; smoke or drink heavily ( $>7$ and $>14$ drinks per week for women and men, respectively); were pregnant or planning to be pregnant; were on medication to regulate blood glucose, lipids, and/ or blood pressure; were using anabolic-androgenic steroids; were currently using antioxidant supplements, non-steroidal anti-inflammatory drugs, or nutritional supplements known to stimulate recovery or muscle mass gains. For inclusion, participants were required to be between 18-45 years old and should have continuously exercised for the past year a minimum of 3 days per week ${ }^{1}$, achieving 30 min of vigorous activity ( $\geq 75 \%$ age-predicted maximum heart rate) per session.

To determine the sample size for the study, an a priori power analysis $\left(\mathrm{G}^{*}\right.$ Power, version 3.0.10) was performed with the given $\alpha$, power, and effect size values ${ }^{29}$. The test family was set as an F-test, and the statistical test was set as a repeated-measures analysis of variance (ANOVA) with the following parameters: $\alpha=0.05 ; 1-\beta=0.8$; effect size $=0.5$; number of groups $=2$; repetitions $=4$. Our previous investigation on the same MP ingredient (microalgae Tetraselmis chuii, Oceanix ${ }^{\circledR}$ ) observed an effect size of 0.54 on performance metrics in the countermovement and squat jump, respectively ${ }^{30}$. Thus, we believe that the effect size estimation of 0.5 for the power analysis was practical. The resulting outcome parameters indicated a total sample size of 22, equating to 11 participants per group. In total, 22 participants were enrolled in the study. Nineteen of the enrolled participants completed the study, as three did not complete post-testing procedures (Figure 1). Prior to engaging in any study procedures, written informed consent for participation was obtained from all participants, which was approved by an Institutional Review Board (Protocol number: 0519; IntegReview, Austin, TX, USA), and the study was performed in agreement with the Declaration of Helsinki. This human trial has been registered at clinicaltrials.gov (NCT04315077). Descriptive statistics for baseline characteristics are provided in Table 1.

\section{Study Protocol}

This study was conducted in a randomized, double-blind, placebo-controlled, and parallel manner. Before allocation into testing groups, participants were assessed for maximal strength and explosive strength, as indicated by peak force and peak rate of force development (RFD), respectively, in

Table 1. Baseline Participant Characteristics

\begin{tabular}{|c|c|c|c|}
\hline Variable & $\begin{array}{c}M P(n=10 \\
m=4, f=6)\end{array}$ & $\begin{array}{l}\text { PLA ( } n=9 ; \\
m=4, f=5)\end{array}$ & $p$-value \\
\hline Age (yr) & $28.9 \pm 1.8$ & $30.2 \pm 2.6$ & 0.672 \\
\hline Height (cm) & $171.2 \pm 4.5$ & $173.0 \pm 3.2$ & 0.754 \\
\hline Body Mass $(\mathrm{kg})$ & $71.4 \pm 5.0$ & $74.4 \pm 4.4$ & 0.658 \\
\hline BMI $\left(\mathrm{kg} / \mathrm{m}^{2}\right)$ & $24.1 \pm 1.0$ & $24.7 \pm 1.0$ & 0.664 \\
\hline $\begin{array}{l}\text { Resting HR } \\
\quad(\mathrm{bpm})\end{array}$ & $59 \pm 2$ & $63 \pm 3$ & 0.189 \\
\hline
\end{tabular}

Data are the mean \pm SEM. MP, marine phytoplankton; PLA placebo; HR, heart rate; bpm, beats per minute; $m$, male; $f$, female. Results for $\mathrm{p}$-values are from unpaired, two-tailed $t$-test. 
a maximal effort isometric mid-thigh pull (IMTP). Participants were then stratified into quartiles based on peak force from the IMTP, and participants from each quartile were randomly divided into conditions using a random number generator (random.org). Thereafter, participants underwent baseline testing (Pre), which included the IMTP assessment and saliva sampling to assess sIgA concentration. Immediately following pre-testing, participants were administered their respective test products (Oceanix ${ }^{\circledR}$ or microcrystalline cellulose-based placebo [PLA]), and the participants underwent a 14-day supplement loading protocol. On day 15 of supplementation, the participants began a 5-day intensified resistance training protocol. The participants continued supplementation for two days after completing the supervised training protocol. Approximately 24 and $48 \mathrm{~h}$ after the last training session, the participants were retested in a manner identical to Pre. The study procedures are described below, and Figure 2 represents a study timeline for the human trial.

Supplement Protocol

Following random assignment, the participants were administered either MP or PLA. The treatment supplement was independently examined by Brunswick Laboratories (Southborough, MA, USA) for oxygen radical absorbance capacity (ORAC) expressed in micromole Trolox equivalent ( $\mu \mathrm{mol}$ TE) per gram. The results indicated that the values were high for hydroxyl radicals at $178.71 \mu$ mole TE/gram and superoxide anions at $348.11 \mu$ mole TE/gram, moderate in peroxynitrite and peroxyl radicals at 8.65 and 29.65 $\mu$ mole TE/gram, respectively, and not detectable in singlet oxygen and hypochlorite. The ORAC values for the superoxide anion corresponded with high total values (38000 IU

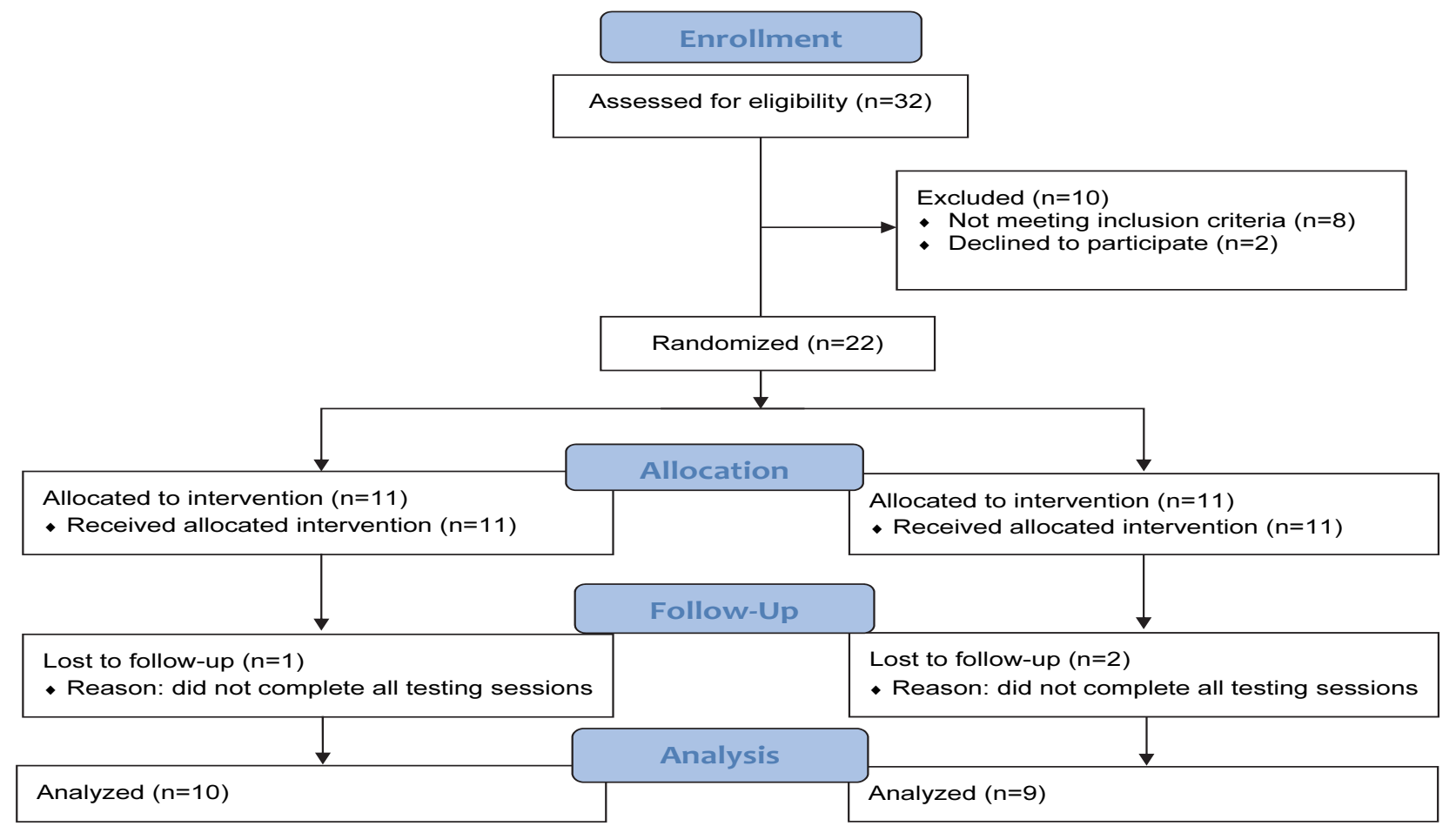

Figure 1. CONSORT Flow Diagram.

Supplementation from days 1 - 21

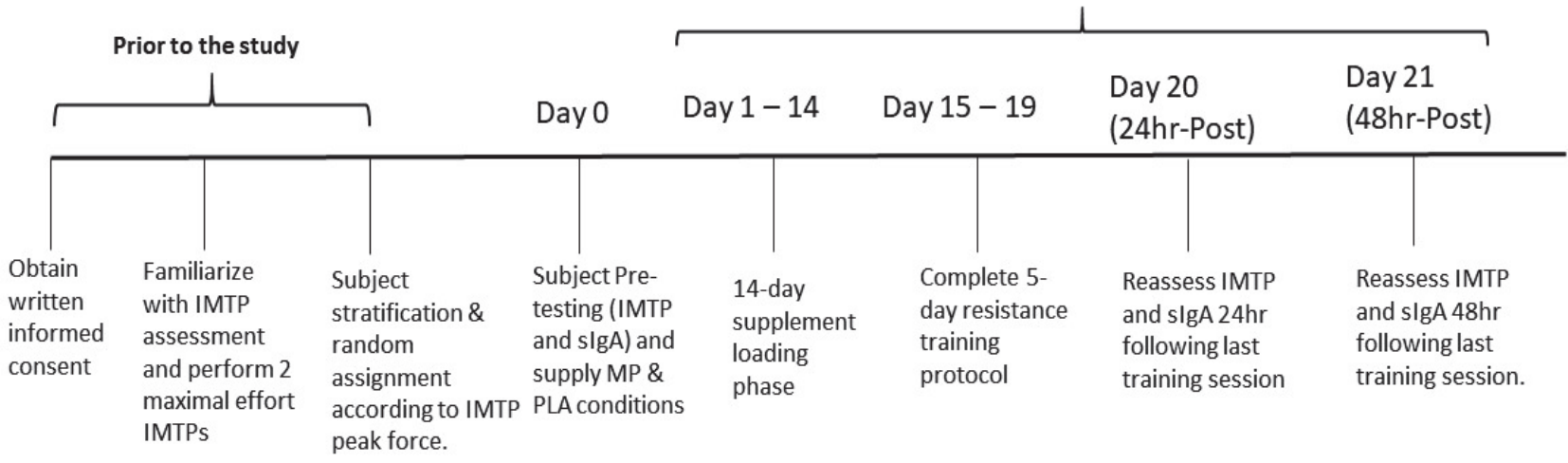


per gram) of SOD in the raw powder. The conditions were stored in visually identical capsules and containers. Participants were required to consume one serving ( $25 \mathrm{mg}$ ) a day, either $30 \mathrm{~min}$ before exercise or with the first meal of the day on non-exercise days. Supplement compliance was assessed by supplement logs and collection of supplement containers, which was calculated to be 95.7 and $93.7 \%$ for MP and PLA, respectively. Participants were instructed to refrain from consuming any other nutritional supplements for the duration of the study that could confound the results.

\section{Resistance Training Protocol}

All participants completed a 5-day resistance training protocol consisting of two lower-, two upper-, and one fullbody workout. The protocol consisted of multiple supersets. Each superset consisted of 2-3 exercises (e.g., C1, C2, and C3), and each superset was performed 3-4 times before progressing to the next superset. Once Superset 1 was completed, participants moved to Superset 2 and so forth. Up to 2 min of rest was allowed between the supersets. Minimal rest was given between exercises within a superset, and participants were instructed to attempt to finish each superset as quickly as possible. All sets performed during the first four days of the protocol were performed with repetition maximum loads such that sets were performed to momentary concentric failure. Whenever participants missed the targeted repetition count by two or more repetitions, the load was decreased by $5 \%$, and whenever participants surpassed the targeted repetition count by two or more, the load was increased by $5 \%$. On day 5 , the participants performed straight sets of Bulgarian split squats to failure for a total of 10 sets ( 5 sets on the right and left legs). Sets were alternated between legs and were separated by 1 min of rest. Volume was tracked by counting the total number of repetitions on the Bulgarian split squats. To set up the exercise, participants were instructed to place one foot on the ground with the other foot elevated on a pad directly behind them. The participants descended downward to a $90^{\circ}$ angle at the knee and ascended upward to complete a repetition. The participants were instructed to only ascend or descend in response to an audible metronome beep at a cadence of $1 \mathrm{~s}$ downward and $1 \mathrm{~s}$ upward. Participants were instructed to complete as many repetitions as possible until concentric muscular failure, which was defined as failure to complete two successive repetitions at the prescribed metronome cadence. The basis of this 5-day resistance training protocol was to induce muscle fatigue to access recovery. Completing loaded sets to a repetition maximum or momentary concentric failure, as implemented in this protocol, can induce muscle fatigue ${ }^{31-33}$. The participants performed a dynamic warm-up before each training session. Immediately following the completion of all resistance training sessions, participants completed a cool-down consisting of static stretching of the major muscle groups targeted within the resistance training session. All stretches were repeated twice and held for $20 \mathrm{~s}$ each. All warm-up, resistance training, and cool-down sessions were supervised by a certified strength and conditioning specialist (NSCA-CSCS), who also monitored training loads for each exercise $^{34}$. Whenever five or more participants were on the training floor at once, two certified strength and conditioning specialists supervised the training floor, and a maximum of 10 participants was allowed on the training floor on days 1-4. On day 5, a maximum of five participants was allowed on the floor, and two certified strength and conditioning specialists were on the training floor at all times during the protocol. All training sessions were completed with at least $24 \mathrm{~h}$ of recovery from the previous training session. A description of the resistance training protocol is provided in Table 2.

\section{Maximal IMTP}

Each participant was tested for maximal isometric strength and peak explosive strength in the IMTP performed in an Olympic-style half rack to allow fixation of the bar at any height. Participants were secured to the bar using

Table 2. Resistance Training Protocol

\begin{tabular}{|c|c|c|c|c|c|c|c|c|c|c|c|c|c|}
\hline \multicolumn{3}{|c|}{ DAY 1} & \multicolumn{3}{|c|}{ Day 2} & \multicolumn{3}{|c|}{ Day 3} & \multicolumn{3}{|c|}{ Day 4} & \multicolumn{2}{|c|}{ Day 5} \\
\hline & Exercise & $\begin{array}{l}\text { Sets } \mathrm{x} \\
\text { Reps }\end{array}$ & & Exercise & $\begin{array}{l}\text { Sets } \mathrm{x} \\
\text { Reps }\end{array}$ & & Exercise & $\begin{array}{l}\text { Sets } \mathrm{x} \\
\text { Reps }\end{array}$ & & Exercise & $\begin{array}{l}\text { Sets } \mathrm{x} \\
\text { Reps }\end{array}$ & Lower & $\begin{array}{l}\text { Sets } \mathrm{x} \\
\text { Reps }\end{array}$ \\
\hline A1) & $\begin{array}{l}\text { Trap Bar } \\
\text { Deadlift }\end{array}$ & $4 \times 8$ & A1) & Chin-Ups & $4 \times 8$ & A1) & DB Snatch & $4 \times 8 \mathrm{e}$ & A1) & BB Row & $4 \times 8$ & $\begin{array}{l}\text { Bulgarian } \\
\text { Split Squat }\end{array}$ & $5 \times$ Failure e \\
\hline A2) & $\begin{array}{l}\text { MB } \\
\text { Jump } \\
\text { Slam }\end{array}$ & $4 \times 8$ & A2) & $\begin{array}{l}\text { DB } \\
\text { Shoulder } \\
\text { Press }\end{array}$ & $4 \times 8$ & A2) & $\begin{array}{l}\text { Repeated } \\
\text { Pause } \\
\text { Jumps }\end{array}$ & $4 \times 5$ & A2) & $\begin{array}{l}\text { Landmine } \\
\text { Press }\end{array}$ & $4 \times 8 e$ & & \\
\hline B1) & $\begin{array}{l}\text { SL Romanian } \\
\text { Deadlift }\end{array}$ & $4 \times 8 e$ & B1) & DB Row & $4 \times 8 \mathrm{e}$ & B1) & $\begin{array}{l}\text { DB Lateral } \\
\text { Lunges }\end{array}$ & $3 \times 8 e$ & B1) & DB Press & $4 \times 8 e$ & & \\
\hline B2) & $\begin{array}{l}\text { DB } \\
\text { Walking } \\
\text { Lunge }\end{array}$ & $4 \times 10 y$ & B2) & $\begin{array}{l}\text { Alternating } \\
\text { DB Floor } \\
\text { Press }\end{array}$ & $4 \times 6 e$ & B2) & $\begin{array}{l}\text { DB Curl } \\
\text { to Press }\end{array}$ & $3 \times 8$ & B2) & $\begin{array}{l}\text { Renegade } \\
\text { Rows }\end{array}$ & $4 \times 8 e$ & & \\
\hline $\mathrm{C} 1)$ & $\begin{array}{l}\text { Prowler } \\
\text { Push }\end{array}$ & $3 \times 20 y$ & C1) & $\begin{array}{l}\text { Leopard } \\
\text { Crawl }\end{array}$ & $3 \times 10 y$ & C1) & $\begin{array}{l}\text { KB Goblet } \\
\text { Squat }\end{array}$ & $3 \times 8$ & C1) & BB Curls & $3 \times 8$ & & \\
\hline C2) & Lateral Lunge & $3 \times 10 e$ & $\mathrm{C} 2)$ & Push-ups & $3 \times 10$ & $\mathrm{C} 2)$ & Deadbug & $3 \times 8$ & $\mathrm{C} 2)$ & Bench Dips & $3 \times 8$ & & \\
\hline & & & C3) & $\begin{array}{l}\text { Single Leg } \\
\text { Jackknife }\end{array}$ & $3 \times 10 e$ & C3) & $\begin{array}{l}\text { Inverted } \\
\text { Row }\end{array}$ & $3 \times 8$ & C3) & $\begin{array}{l}\text { DB Lateral } \\
\text { Raise }\end{array}$ & $3 \times 8$ & & \\
\hline
\end{tabular}

Abbreviations: $\mathrm{e}=$ each side; $\mathrm{y}$ = yards; $\mathrm{BB}=$ barbell; $\mathrm{DB}=$ dumbbell; $\mathrm{KB}=$ kettlebell; $\mathrm{SL}=$ single leg

Exercises marked with ' $A$ ' and ' $B$ ' indicate that the exercises are performed in a superset fashion. Exercises marked with ' $A$ ', ' $B$ ', and ' $C$ ' indicate that the exercises are performed as a tri-set. 
lifting straps and athletic tape. Utilizing a pronated clean grip, participants were instructed to assume a body position similar to the second pull of the snatch and clean. The knee angle was confirmed between $125-135^{\circ}$ using a hand-held goniometer, and the hip angle was set at approximately $175^{\circ}$. Once the body positioning was stabilized, each participant was given a countdown. Minimal pre-tension was allowed to eliminate slack prior to IMTP initiation. Each participant performed two warm repetitions, one at $50 \%$ and the other at $75 \%$ of the perceived maximum effort. Thereafter, participants completed two maximal IMTP lasting 6 seconds, separated by 2-3 minutes rest. Participants were instructed to pull fast and hard and were given strong verbal encouragement during the assessment. Strength was determined by measuring the peak force attained during the IMPT pull. Peak explosive strength was determined as the peak rate of force development (RFD) during the maximal pulling movement. Force production was recorded using a linear position transducer ${ }^{35}$.

\section{SIgA Levels}

Salivary immunoglobulin A samples were collected using IPRO Oral Fluid Collector (OFC) kits (Soma Bioscience; Wallingford, UK). The OFC kits collect $0.5 \mathrm{~mL}$ of oral fluid and contain a color-changing volume adequacy indicator within the swab, giving collection times typically in the range of 20-50 $\mathrm{s}^{36}$. All samples were collected following a $10 \mathrm{~h}$ overnight fast. The samples were analyzed using an IPRO POC lateral flow device (LFD; Soma Bioscience; Wallingford, UK), specific for SIgA, in an IPRO LFD Reader. Two drops of saliva/buffer mix from the OFC were added to the sample window of the LFD. The liquid runs the length of the test strip via lateral flow, creating control and test line visible in the test window. Ten minutes after the sample was added, the test line intensity was measured in an IPRO LFD Reader and converted to a quantitative value.

\section{Rat Trial}

Rat Study Protocol

The protocol included 8-week-old male Wistar albino rats with a body mass between 200-250 g and free of any detectable disease. Rats $(n=28)$ were obtained from the Laboratory Animal Research Center, Firat University (Elazig, Turkey). Rats were kept in identical cages in the same room under standard conditions $\left(22 \pm 2^{\circ} \mathrm{C}\right.$ temperature, $55 \pm$ 5\% humidity, $12 \mathrm{~h}$ light/dark cycle). Ethical permission for the experiment was obtained from the Animal Experimentation Ethics Committee of Firat University (2019/139-206) according to the relevant laws, guidelines, and restrictions.

A random number generator (random.org) was used to randomly assign rats to one of four possible conditions in a blinded fashion: (i) control (no exercise and no supplement [CON]), (ii) exercise only (E), (iii) exercise + marine phytoplankton $1(2.55 \mathrm{mg} / \mathrm{kg} / \mathrm{day}$, [E + MP1]), and (iv) exercise + marine phytoplankton $2(5.1 \mathrm{mg} / \mathrm{kg} /$ day [E + MP2]). A total of seven rats were assigned to each condition, and body mass was not significantly different between the conditions $(\mathrm{p}>0.05$; mean \pm SEM: Con $=207.3 \pm 4.9 \mathrm{~g}, \mathrm{E}=217.7 \pm$ $7.6 \mathrm{~g}, \mathrm{E}+\mathrm{MP} 1=211.7 \pm 9.8 \mathrm{~g}, \mathrm{E}+\mathrm{MP} 2=214.6 \pm 11.5 \mathrm{~g})$. Marine phytoplankton and vehicle (physiological saline) were administered orally via gavage daily before exercise during the experimental period (6 weeks).

Rats in exercising conditions were subjected to treadmill exercise on a motorized rodent treadmill (Commat Limited, Ankara, Turkey). The treadmill contained a stimulus grid at the back end of the treadmill, providing an electric shock when the animal placed its paw on the grid. The apparatus had a 5-lane animal exerciser, utilizing a single belt unit divided by walls suspended over the tread surface. To eliminate diurnal variations, all exercise tests were performed during the same time of the day. A week of adaptation was provided as a pre-training practice for the animals to familiarize themselves with the treadmill equipment and handling. To do so, the rats in the exercise training groups were accustomed to treadmill exercise over a 5-day period: (i) day $1,10 \mathrm{~m} / \mathrm{min}, 10 \mathrm{~min}$; (ii) day 2, $20 \mathrm{~m} / \mathrm{min}, 10 \mathrm{~min}$; (iii) day $3,25 \mathrm{~m} / \mathrm{min}, 10 \mathrm{~min}$; (iv) day 4, $25 \mathrm{~m} / \mathrm{min}, 20 \mathrm{~min}$; and (v) day $5,25 \mathrm{~m} / \mathrm{min}, 30 \mathrm{~min}$. After adaptation for a week to the treadmill system to assess the novel and stress impacts, the rats in treadmill exercise groups ran on the treadmill at $25 \mathrm{~m} / \mathrm{min}, 45 \mathrm{~min} /$ day, and five days per week for 6 weeks according to the protocol described by Liu et al. ${ }^{37}$. Figure 3

\section{Male Wistar albino rats ( $n=7 /$ condition) \\ - Control (no exercise \& no supplement) \\ - Exercise only (E) \\ - $E+M P 1(2.55 \mathrm{mg} / \mathrm{kg} /$ day $)$ \\ - $E+M P 2(5.1 \mathrm{mg} / \mathrm{kg} /$ day $)$}

Day -7 - 0

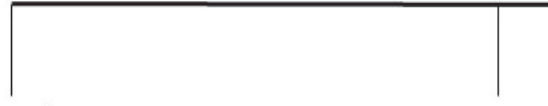

One week

adaptation period

to the treadmill

protocols
Daily supplementation

Treadmill exercise $45 \mathrm{~min} /$ day and 5 days/week 
shows the study timeline for the rat trial.

\section{Sample Collection}

At the end of the study, animals in all groups were sacrificed by cervical dislocation under xylazine $(10 \mathrm{mg} / \mathrm{kg}$, i.m. and ketamine $\left(50 \mathrm{~m} /{ }^{*} \mathrm{~kg}, \mathrm{i} . \mathrm{m}.\right)$ anesthesia on the same day; thereafter, blood and gastrocnemius muscle were collected. Serum samples were obtained by collecting blood samples in biochemical gel tubes after centrifugation $(5000 \mathrm{rpm}$ at $4^{\circ} \mathrm{C}$ for $10 \mathrm{~min}$ ). Samples of the gastrocnemius muscle (taken from approximately the same location each time) were quickly removed, placed on ice, and stored at $-80^{\circ} \mathrm{C}$ until further analysis.

\section{Biochemical Analysis}

Serum concentrations of biochemical parameters were assayed using a portable automated chemistry analyzer (Samsung LABGEO PT10, Samsung Electronics Co., Suwon, Korea). Interleukin-1 beta (IL-1 $\beta$ ) and tumor necrosis factor-alpha (TNF $\alpha$ ) kits were used to analyze the levels of these parameters (Linco Research Inc., St. Charles, MO, USA) with an ELISA instrument (Elx-800, Bio-Tek Instruments Inc., Vermont, USA).

Malondialdehyde (MDA) concentration in muscle tissue was measured using an HPLC device with a Shimadzu UVVis SPD-10 AVP detector, a CTO-10 AS VP column, and a mobile phase comprising $30 \mathrm{mM} \mathrm{KH} \mathrm{PO}_{4}$ and methanol (82.5: $17.5, \mathrm{v} / \mathrm{v})$ at a flow rate of $1.2 \mathrm{~mL} / \mathrm{min}$. Tissue homogenates $(10 \%, \mathrm{w} / \mathrm{v})$ were prepared in $10 \mathrm{mM}$ phosphate buffer and centrifuged at $13.000 \times \mathrm{g}$ for $10 \mathrm{~min}$ at $4{ }^{\circ} \mathrm{C}$.

\section{Western Blot Analysis}

Muscle samples were pooled and homogenized in $1 \mathrm{~mL}$ of ice-cold hypotonic buffer A containing $10 \mathrm{mM}$ HEPES (pH 7.8), $10 \mathrm{mM} \mathrm{KCl,} 2 \mathrm{mM} \mathrm{MgCl} 2,1 \mathrm{mM}$ DTT, $0.1 \mathrm{mM}$ EDTA, and $0.1 \mathrm{mM}$ phenylmethylsulfonyl fluoride (PMSF). Eighty microliters of 10\% Nonidet P-40 (NP-40) solution was added to the homogenates, and the mixture was then centrifuged for $2 \mathrm{~h}$ at $14,000 \times \mathrm{g}$. Buffer $\mathrm{A}(500 \mu \mathrm{L})$ plus 40 $\mu \mathrm{L}$ of $10 \%$ NP-40 was used to wash the precipitates containing nuclei. The precipitates were then centrifuged and resuspended in $200 \mu \mathrm{L}$ of buffer $\mathrm{C}$ [ $50 \mathrm{mM}$ HEPES ( $\mathrm{pH} 7.8$ ), $50 \mathrm{mM} \mathrm{KCl}, 300 \mathrm{mM} \mathrm{NaCl}, 0.1 \mathrm{mM}$ EDTA, 1 mM DTT, 0.1 $\mathrm{mM}$ PMSF, and $20 \%$ glycerol], and centrifuged for $30 \mathrm{~min}$ at $14.800 \times \mathrm{g}$. The supernatant was then transferred to a new tube. Western blot analyses were performed on tissue homogenates for IL- $1 \beta$ and TNF- $\alpha$. Protein concentration was measured using the Lowry method. A pool of tissue samples was created with the same amount of protein $(50 \mu \mathrm{g})$ and the samples were electrophoresed on 12\% SDS-PAGE gels, followed by transfer to a nitrocellulose membrane (Schleicher and Schuell Inc., Keene, NH, USA). The primary antibody for $\beta$-actin was delivered (Abcam Inc., UK) and diluted $(1: 1000)$ in the same buffer containing $0.05 \%$ Tween- 20 . The nitrocellulose membranes were incubated overnight at $4^{\circ} \mathrm{C}$. After washing, the blots were incubated with goat anti-mouse IgG (horseradish peroxidase-conjugated secondary antibody) at a dilution of 1:5000 (Abcam, Cambridge, UK).
Protein bands were quantified by scanning densitometry using an image analysis system (ImageJ; National Institutes of Health, Bethesda, USA). The protein bands were normalized to the corresponding $\beta$-actin band values and compared with those of the control group.

\section{Statistical Analysis}

Before performing statistical analysis, data were tested for normality and variance using the Shapiro-Wilk test and Levene's test, respectively. A mixed model analysis of variance (ANOVA) was performed assuming group (MP and PLA) as the between-participant factor, time (Pre, 24 h-Post, and 48 h-Post) as the within-participant factor, and participants as a random factor. No gender effects were observed on any reported dependent variable; therefore, the data were collapsed. In the rat trial, one-way ANOVA was performed. When a significant $F$ value was obtained, post-hoc testing with Tukey's adjustment was performed for multiple comparisons. The absolute mean difference $\left(\right.$ Time $_{2}-$ Time $\left._{1}\right)$ was analyzed to compare groups with unpaired, two-tailed $t$-test for select variables (peak RFD). Additionally, we reported the mean difference and upper and lower limit values of $95 \%$ confidence intervals $(95 \% \mathrm{CI})$ of the mean difference for within-group comparisons, as this approach allows variable change due to supplementation to be investigated, rather than only the level of statistical significance. In this regard, the confidence interval includes the value range in which the true population mean of the difference is likely to be contained. Confidence intervals that did not contain zero were considered significant at $p<0.05^{38}$. Lastly, within-group effect sizes (ES) were calculated as [( $\left.\mathrm{Mean}_{2}-\mathrm{Mean}_{1}\right) /$ Pooled $S D$ ). For all analyses, the significance level was set at $\mathrm{p} \leq 0.05$. Results are expressed as the mean and standard error of the mean (SEM) unless otherwise noted. Data were analyzed using SPSS software (IBM SPSS, Version 26.0; SPSS, Inc., Chicago, IL, USA) and GraphPad Prism 8 software (GraphPad Software, Inc., La Jolla, CA, USA).

\section{RESULTS}

\section{Human Trial}

IMTP

No significant differences existed between groups at Pre for IMTP peak force $(\mathrm{p}=0.832)$ and peak rate of force development (RFD, $\mathrm{p}=0.519)$. No significant main effects or interactions were detected for peak force $(p>0.05)$. A significant main effect of time was indicated for peak RFD $(\mathrm{p}=0.007)$. However, confidence interval analysis suggested that only the PLA group experienced significantly decreased peak RFD at 48 h-Post compared to 24 h-Post (PLA: me$\mathrm{an}_{\text {diff }}=-1908,95 \% \mathrm{CI}=-3768$ to $-48 \mathrm{~N} * \mathrm{~s}^{-1}, \mathrm{ES}=0.46$, $\mathrm{p}=0.043$; MP: mean $_{\text {diff }}=-949,95 \% \mathrm{CI}=-2713$ to $688 \mathrm{~N}$ * $\left.\mathrm{s}^{-1}, \mathrm{ES}=0.04, \mathrm{p}=0.306\right)$ and Pre (PLA: mean $_{\text {diff }}=-2202,95 \%$ $\mathrm{CI}=-4062$ to $-342 \mathrm{~N}^{*} \mathrm{~s}^{-1}, \mathrm{ES}=0.51, \mathrm{p}=0.017$; MP: meandiff $=-949,95 \% \mathrm{CI}=-2713$ to $688 \mathrm{~N}^{*} \mathrm{~s}^{-1}, \mathrm{ES}=0.31, \mathrm{p}=0.396$; Figure 4A). Additionally, the absolute mean difference from Pre to 48 h-Post in peak RFD was significantly different be- 
tween groups (PLA: $-2202 \pm 981$ vs. MP: $-949 \pm 716 \mathrm{~N}^{*} \mathrm{~s}^{-1}$, $\mathrm{p} \leq 0.05$; Figure 4B).

\section{SIgA Levels}

No significant differences were observed between the groups at Pre for $\operatorname{sg} \mathrm{A}(\mathrm{p}=0.863)$. A significant main effect of time was detected for $\operatorname{sIgA}(\mathrm{p}=0.004)$. Confidence interval analysis suggest that only the PLA group demonstrated significantly lower sIgA from Pre to 48 h-Post (PLA: mean $_{\text {diff }}=202.8,95 \% \mathrm{CI}=26.7$ to $379.0 \mu \mathrm{g} / \mathrm{mL}, \mathrm{ES}: 1.12$, $\mathrm{p}=0.021$; MP: mean $_{\text {diff }}=148.8,95 \% \mathrm{CI}=-22.9$ to $316.0 \mu \mathrm{g} /$ $\mathrm{mL}, \mathrm{ES}: 0.66, \mathrm{p}=0.108$; Figure 5).

\section{Exercise Protocol Training Volume on Day 5}

A significant main effect of set was detected $(\mathrm{p}<0.001$; Figure 6), whereby both groups completed significantly lower repetitions on sets $2-5$ compared to set $1\left(\right.$ mean $_{\text {diff }}=$
-46 to -40 repetitions, $\mathrm{p}<0.001$ ). The unpaired $t$-test indicated no significant differences $(\mathrm{p}=0.918)$ between groups for total training volume during the (muscle failure) training session on day 5 (mean total repetitions per participant: MP $=250 \pm 112$, PLA $=243 \pm 149$; group total repetition sum: $\mathrm{MP}=2495$, PLA $=2189$ ).

\section{Rat Trial}

Levels of IL- $1 \beta$ and TNF- $\alpha$

No significant differences were noted between the CON and $\mathrm{E}$ arms for IL-1 $\beta$ levels ( $\mathrm{p}>0.05)$, whereas both $\mathrm{E}+\mathrm{MP} 1$ $\left(m^{2} n_{\text {diff }}=-0.23\right.$ au, ES: $\left.2.19, p<0.01\right)$ and E+MP2 $\left(\right.$ mean $_{\text {diff }}=$ $-0.45 \mathrm{au}, \mathrm{ES}: 7.36, \mathrm{p}<0.001)$ demonstrated significantly lower IL-1 $\beta$ levels compared to CON. Additionally, E+MP2 revealed significantly lower IL-1 $\beta$ levels compared to the exercise and $\mathrm{E}+\mathrm{MP} 1 \mathrm{arms}\left(\mathrm{mean}_{\mathrm{diff}}=-0.22 \mathrm{au}, \mathrm{ES}=2.34\right.$, $\mathrm{p}<0.01$; Figure 7A). TNF- $\alpha$ levels were significantly low-
(A)

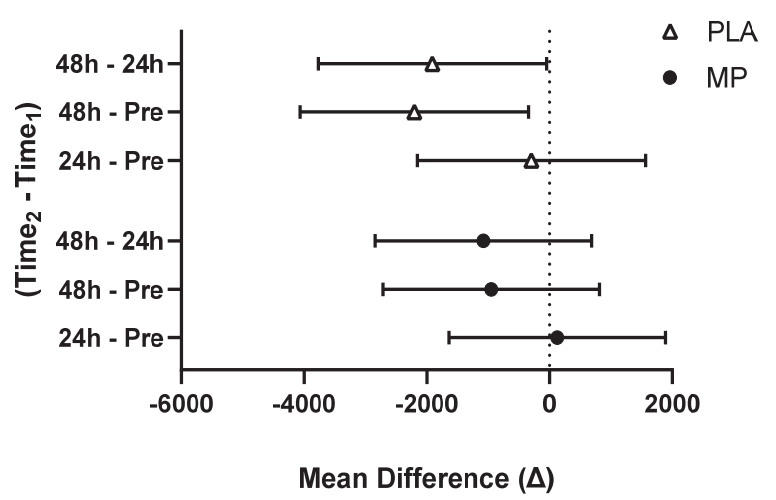

(B)

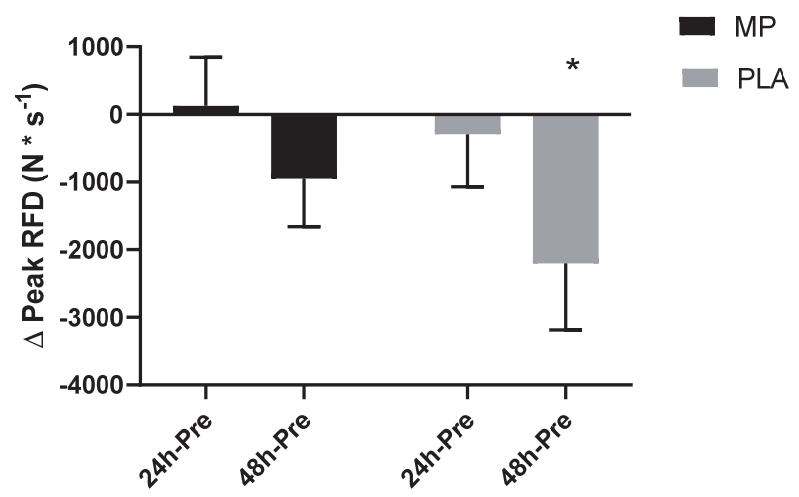

${ }^{*}=$ significantly difference between groups $(p<0.05)$

\section{Figure 4. IMTP Peak Rate of Force Development at 95\% CI Difference (A) and Delta Change (B).}

The $95 \% \mathrm{Cl}$ of the mean difference of $\mathrm{Time}_{2}-\mathrm{Time}_{1}(\mathrm{~A})$ and the delta change from Pre values (B) for IMTP peak RFD. Figure 4A shows the mean with the upper and lower limits of the $95 \% \mathrm{Cl}$. Figure 4B shows a bar chart for the mean values and error bars for the standard error of the mean. ${ }^{*}=$ significantly different between conditions (two-tailed, unpaired $t$-test; $p<0.05$ ). The conditions were marine phytoplankton (MP) and placebo (PLA). Abbreviations: IMPT, isometric mid-thigh pull; RFD, rate of force development; Cl: confidence interval.

(A)

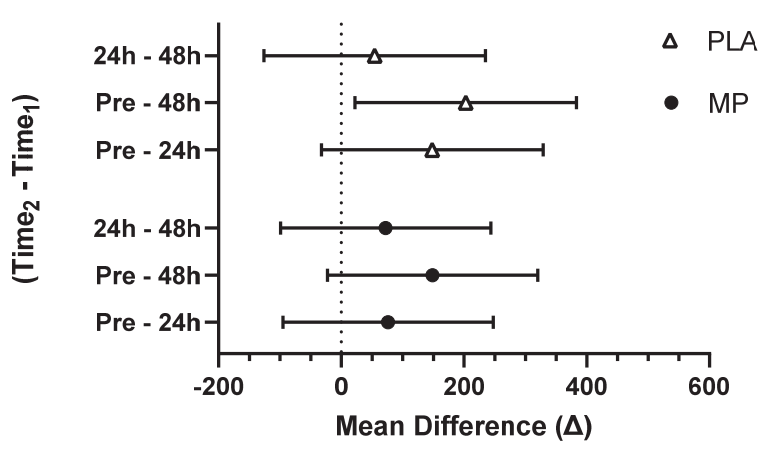

(B)

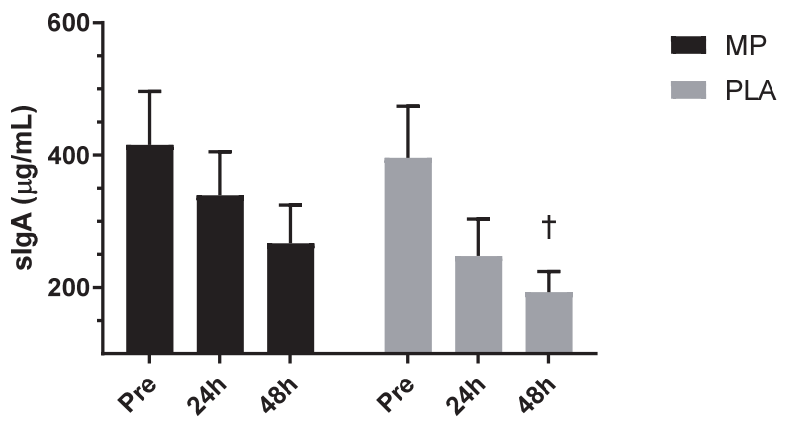

$\dagger=$ Significantly lower than Pre 
er than $\mathrm{CON}$ in $\mathrm{E}\left(\mathrm{mean}_{\text {diff }}=-0.19\right.$ au, $\left.\mathrm{ES}=2.12, \mathrm{p}<0.01\right)$, $\mathrm{E}+\mathrm{MP} 1\left(\mathrm{mean}_{\mathrm{diff}}=-0.35 \mathrm{au}, \mathrm{ES}=4.58, \mathrm{p}<0.001\right)$, and $\mathrm{E}+\mathrm{MP} 2\left(\right.$ mean $\left._{\text {diff }}=-0.47 \mathrm{au}, \mathrm{ES}=6.21, \mathrm{p}<0.001\right)$. Furthermore, TNF- $\alpha$ levels in both supplement arms were lower than those in the exercise arm (E+MP1: mean $_{\text {diff }}:-0.16 \mathrm{au}$, ES: 2.02, p<0.01; E+MP2: mean $_{\text {diff: }}-0.28$ au, ES: 3.57, $\mathrm{p}<0.001)$, and $\mathrm{E}+\mathrm{MP} 2$ was lower than E+MP1 ( mean $_{\text {diff: }}$ : -0.12 au, ES: $1.86, \mathrm{p}<0.05$; Figure $7 \mathrm{~B}$ ). Figure 7 displays the mean and SEM of these results.

Regarding IL-1 $\beta$ serum concentration, no significant differences were noted between the CON, E, and E+MP1 groups ( $p>0.05$ ). However, IL-1 $\beta$ concentration was lower in $\mathrm{E}+\mathrm{MP} 2$ compared to that in CON ( mean $_{\text {diff: }}:-3.14 \mathrm{pg} / \mathrm{mL}$, ES: $2.47, p<0.01)$ and $\mathrm{E}\left(\mathrm{mean}_{\text {diff }}=-3.40 \mathrm{pg} / \mathrm{mL}, \mathrm{ES}: 2.32\right.$, $\mathrm{p}<0.01$ ) but not significantly different than that in E+MP1 $(p>0.05)$. For TNF- $\alpha$ concentration, levels were significantly lower in E+MP1 and E+MP2 compared to those in CON

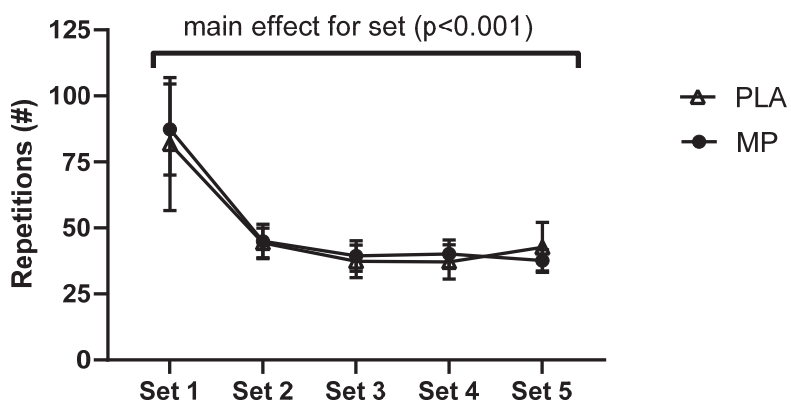

Figure 6. Repetition Count per Set.

The repetition count for each set of the day 5 exercise protocol. The counts are the sum of repetitions completed on the left and right egs. The Figure 6 shows a line graph with the mean values and error bars for the standard error of the mean. The conditions were marine phytoplankton (MP) and placebo (PLA).

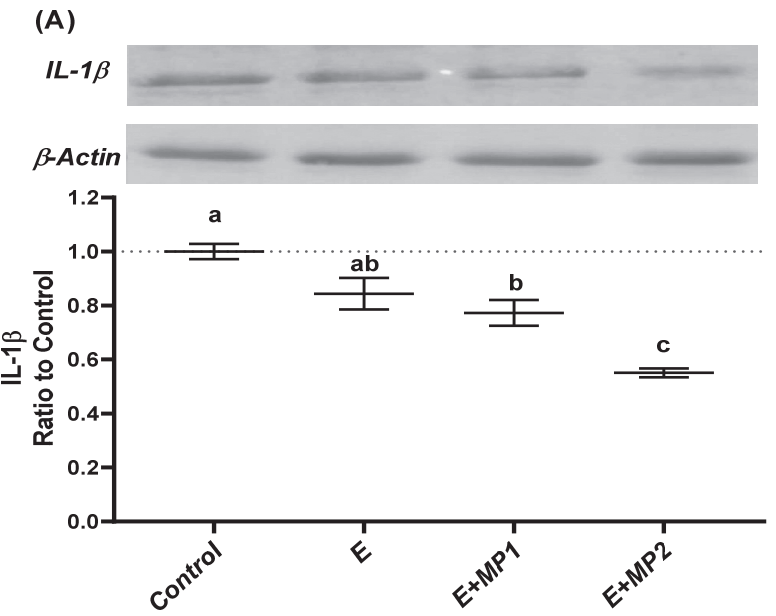

$\left(\mathrm{E}+\mathrm{MP} 1:\right.$ mean $_{\text {diff }}=-3.13 \mathrm{pg} / \mathrm{mL}, \mathrm{ES}: 3.55, \mathrm{p}<0.01 ; \mathrm{E}+\mathrm{MP} 2:$ mean $\left._{\text {diff }}=-4.64 \mathrm{pg} / \mathrm{mL}, \mathrm{ES}: 4.43, \mathrm{p}<0.001\right)$ and $\mathrm{E}(\mathrm{E}+\mathrm{MP} 1$ : mean $_{\text {diff }}=-1.83 \mathrm{pg} / \mathrm{mL}$, ES: $1.32, \mathrm{p}<0.05$; E+MP2: mean $_{\text {diff }}=$ $-3.34 \mathrm{pg} / \mathrm{mL}, \mathrm{ES}: 2.23, \mathrm{p}<0.01)$. Figure 8 displays the mean and SEM of these results.

\section{Muscle MDA}

Muscle MDA concentration was lowered by exercise and exercise plus supplementation compared to CON $\left(\mathrm{E}: \mathrm{mean}_{\text {diff }}=-0.24 \mathrm{nmol} / \mathrm{mg}, \mathrm{ES}=2.00, \mathrm{p}<0.05 ; \mathrm{E}+\mathrm{MP} 1\right.$ : mean $_{\text {diff }}=-0.46 \mathrm{nmol} / \mathrm{mg}, \mathrm{ES}: 3.84, \mathrm{p}<0.01$; E+MP2: me$\mathrm{an}_{\mathrm{diff}}=-0.69 \mathrm{nmol} / \mathrm{mg}$, ES: $\left.5.23, \mathrm{p}<0.001\right)$. Exercise plus supplementation lowered MDA concentration more than $\mathrm{E}$ alone $\left(\mathrm{E}+\mathrm{MP} 1\right.$ : mean $_{\text {diff }}=-0.22 \mathrm{nmol} / \mathrm{mg}, \mathrm{ES}: 2.02, \mathrm{p}<0.05$; $\mathrm{E}+\mathrm{MP} 2:$ mean $\left._{\text {diff }}=-0.45 \mathrm{nmol} / \mathrm{mg}, \mathrm{ES}: 3.76, \mathrm{p}<0.01\right)$, and levels in E + MP2 were lower than E + MP1 ( mean $_{\text {diff }}=-0.23$ $\mathrm{nmol} / \mathrm{mg}, \mathrm{ES}=1.92, \mathrm{p}<0.05$; Figure 9).

\section{DISCUSSION}

The primary purpose of this study was to examine the effects of MP supplementation on functional indices of muscle damage and, secondarily, its underlying impact on immune function in a human model following a short-term, muscle-damaging bout of anaerobic exercise. The primary purpose of the rat model was to mechanistically investigate if MP could lower the proinflammatory immunoregulatory cytokine response. Secondarily, we sought to determine if the proinflammatory cytokine response is mediated by reduced oxidative stress. We hypothesized that the ingredient would mitigate decrements in functional indices of muscle damage and preserve immune function following a challenging short-term intensified exercise protocol. Mechanis-

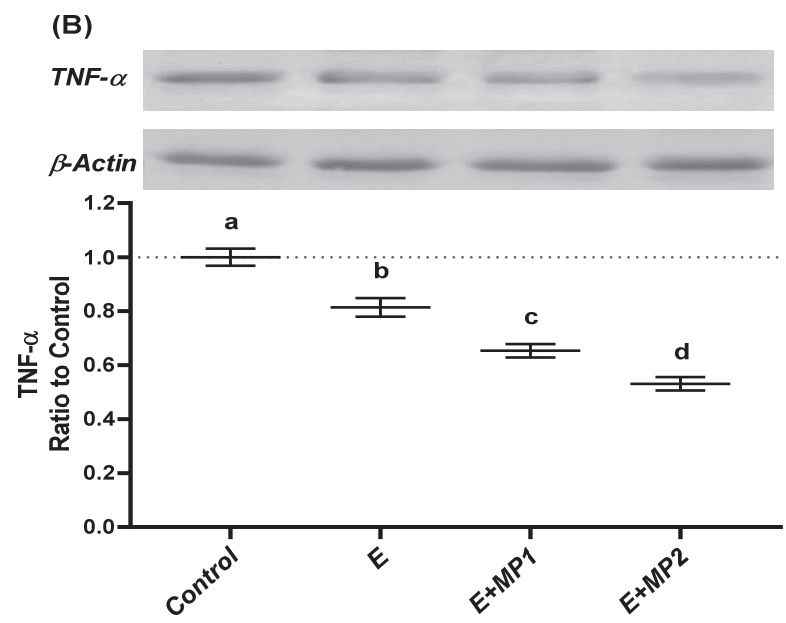

Different scripts $(a-d)$ indicate significant differences among groups $(p<0.05)$ 
(A)

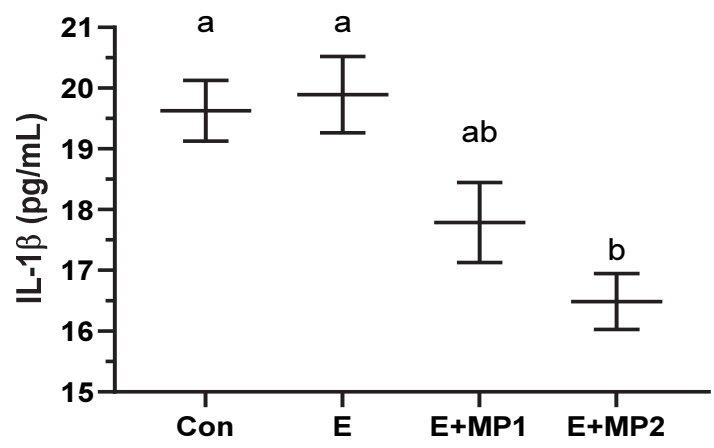

(B)

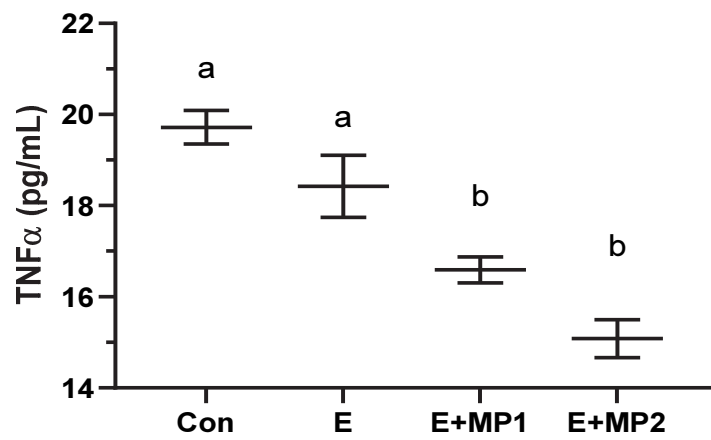

Different symbols $(a-d)$ indicate significant differences between groups $(p<0.05)$

Figure 8. Serum Concentrations of IL-1 $\beta(A)$ and TNF- $\alpha(B)$.

Mean and standard error for serum concentrations of IL-1 $\beta(A)$ and TNF- $\alpha(B)$ in rats following 6 weeks of motorized treadmill exercise. Differen symbols (a-d) indicate statistical differences among the groups (ANOVA and Tukey's post-hoc test; $p<0.05)$. The conditions were as follows: control (CON), exercise (E), exercise + marine phytoplankton $1(2.55 \mathrm{mg} / \mathrm{kg} / \mathrm{day},[\mathrm{E}+\mathrm{MP} 1])$, and Exercise + marine phytoplankton 2 (5.1 mg $\mathrm{kg} /$ day [E + MP2]). Abbreviations: IL-1 $\beta$, interleukin-1 $\beta$; TNF- $\alpha$, tumor necrosis factor-alpha.

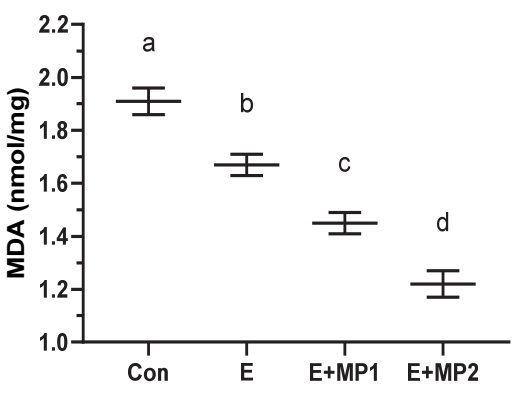

Different scripts $(a-d)$ indicate significant differences among groups $(p<0.05)$

Figure 9. Muscle MDA Concentration.
Mean and standard error for muscle MDA concentration in rats
following 6 weeks of motorized treadmill exercise. Different symbols
(a-d) indicate statistical differences among the groups (ANOVA and
Tukey's post-hoc test; $p<0.05)$. The conditions were as follows:
control (CON), exercise (E), exercise + marine phytoplankton $1(2.55$
$\mathrm{mg} / \mathrm{kg} /$ day, [E + MP1]), and exercise + marine phytoplankton 2 (5.1
$\mathrm{mg} / \mathrm{kg} /$ day [E + MP2]). Abbreviations: MDA, malondialdehyde.

tically, we hypothesized that MP would decrease proinflammatory cytokines and oxidative stress relative to the control. The primary findings of this study support our hypotheses. Specifically, MP supplementation blunted increases in functional indices of muscle damage and prevent the decline in immune function, as indicated by sIgA levels. Mechanistically, we found that the administration of MP lowered intramuscular oxidative stress with a concomitant decline in proinflammatory cytokines compared to the control.

The phenomenon of contraction-induced skeletal muscle damage, also referred to as minor contractile-induced injury, has received considerable interest in the medical literature. Physical activity inducing mechanical overload, muscle stretching, or both have been causative factors of muscle damage ${ }^{39-42}$, which has been exhibited by structural disruption of myofilaments ${ }^{43}$, sarcolemma damage ${ }^{44}$, loss of muscle fiber integrity ${ }^{44}$, leakage of muscle proteins into the blood ${ }^{44,45}$, and acute inflammatory responses ${ }^{3,46}$. However, far less is known regarding the implications of these physiological associations of muscle damage on functional indices (i.e., muscle force parameters). From both practical and clinical science perspectives, the damage criteria should be related to muscle function. Rate of force development, also referred to as explosive strength, has gained strong support as a functional indicator of muscle damage ${ }^{47}$. Explosive strength is the speed or rate at which an individual can develop force ${ }^{48}$. This motor ability predicts performances of daily functional tasks to a greater degree than maximal voluntary contraction, which is seldom expressed in the time constraints of daily activity ${ }^{48}$. Moreover, this measure has been determined to be more sensitive to detect acute (24-72 h) ${ }^{47}$ changes in neuromuscular function as compared to nontime-constrained maximal contraction measures. While this study consisted of intense and high-volume exercise, our results indicated that maximal strength was sustained. However, explosive strength in the PLA group was significantly lower at $24(-27 \%)$ and $48(-30 \%) \mathrm{h}$ following the muscle-damaging event compared to Pre levels. Additionally, the absolute mean difference in explosive strength from Pre to $48 \mathrm{~h}$-Post training was lower in the PLA group than in the MP group.

Exercise-induced fatigue can occur both peripherally and centrally. Peripheral fatigue occurs primarily in skeletal muscle and is exacerbated by the depletion of energy stores, accumulation of metabolic by-products, and muscle damage from mechanical and chemical disturbances ${ }^{49}$. In contrast, central fatigue is simply considered a reduction in the ability to maximally activate a given muscle ${ }^{50}$. This type of fatigue can be mediated by group III and IV afferent feedback loops $^{51}$, increased BCAA metabolism ${ }^{52}$, and increased motor cortex excitability ${ }^{50}$.

The impairment in explosive strength performance combined with the reduction in time to reach maximal force 
allowed us to theorize that A) the exercise stimulus was sufficient to induce neuromuscular (central) and peripheral fatigue (damage), and B) the participants completed the post-testing protocol in a state of neuromuscular and/or peripheral fatigue. This hypothesis follows the findings that explosive strength can better detect acute $(24-72 \mathrm{~h})^{47}$ changes in neuromuscular function as compared to non-timeconstrained maximal strength measures. These findings also indicate that MP can sustain anaerobic performance and improve recovery following short-term, high-intensity training.

A new paradigm in exercise physiology posits close communication between immune responses and recovery kinetics $^{53}$. Fragala et al. ${ }^{53}$ suggested that physical exercise elicits a system-wide immune response that is directed at restoring homeostasis. When this response is interrupted, recovery is hindered ${ }^{26,54}$. Studies have reported that immune function can be diminished following acute bouts of heavy repeated exercise $^{13,55,56}$, and individuals engaged in intensive periods of high-intensity training are more susceptible to minor infections ${ }^{54,56}$. For example, according to various surveys, impaired immune function is more common in athletes than in the general population, and infection may last longer in athletes $8,55,57$. This is a concern for trainees, as it is generally recognized that weakened immune function can result in a decrease in exercise performance and the ability to sustain heavy training ${ }^{54}$. Additionally, infections can be associated with the development of chronic fatigue ${ }^{58}$, and training during periods of severe infection can increase the risk of overtraining ${ }^{59}$. Previously, in American football players, the incidence of upper respiratory tract infection increased during periods of intense exercise, while sIgA concentration simultaneously decreased ${ }^{18}$. Likewise, in a study on elite swimmers, sIgA was significantly depressed over a seven-month training period ${ }^{60}$. Both the aforementioned studies demonstrated significant inverse correlations between sIgA concentrations and infection rates. The present study found that $\operatorname{sIgA}$ was significantly reduced in PLA but was maintained in MP following a one-week resistance training protocol. Although speculative, these findings indicate that MP supplementation may improve recovery through an antioxidant immunomodulatory mechanism, which we elaborate on through our mechanistic rat model.

To achieve cellular homeostasis, a balance between ROS production and antioxidant capacity is required. It has been proposed that cellular redox homeostasis is governed by redox-sensitive signaling mechanisms, which react to the amplified formation of ROS by stimulating oxidant scavenger systems ${ }^{61}$. While the immune system coordinates such mechanisms to defend against deleterious pro-oxidant actions in basal conditions, the system may not react sufficiently in moments of rapid and exaggerated ROS formation. For instance, skeletal muscle generates ROS at an accelerated rate during contraction ${ }^{62}$. During bouts of muscle failure, an influx of calcium ions in the cytoplasm due to the overloaded mitochondria provoke greater concentrations of ROS in the cytoplasm ${ }^{63}$. In turn, this stimulates the release of proteases, such as calpains, that degrade muscle proteins, which subsequently increases the permeability of the muscle cell membrane ${ }^{63}$. Additionally, ROS have been shown to directly contribute to muscle damage ${ }^{64}$, which potentially occurs through the peroxidation of phospholipids in the muscle cell membrane ${ }^{65}$. Previous research has confirmed that increased ROS production in response to exercise can cause oxidative modifications of nucleic acids, lipids, proteins, and multiple cellular compounds ${ }^{66-68}$. A significant portion of exercise-induced inflammation within the muscle can be traced to mitochondrial uncoupling and subsequent induction of $\operatorname{ROS}^{6}$. Thus, mechanistically, the contractile-induced inflammatory processes may underlie impaired immunity, at least acutely, as amplified ROS production could cause oxidative and muscle damage, prompt immune cell death, and increase susceptibility to infection ${ }^{6,13}$.

Formation of ROS has been shown to increase proinflammatory cytokine expression ${ }^{12}$ by activating nuclear factor-kappa $\beta(\mathrm{NF}-\mathrm{k} \beta)^{69-72}$. Activated NF- $\mathrm{KB}$ moves from the cytosol and relocates into the nucleus of cytokine-producing cells, increasing the transcription of cytokine mRNA ${ }^{73}$. Proinflammatory cytokines, such as IL- $1 \beta$ and TNF- $\alpha$, orchestrate widespread metabolic changes and modulate immune system activity, enhancing their production ${ }^{73}$. Proinflammatory cytokines induce and mediate catabolic activities $^{74}$, some of which are regulators of the ubiquitin-proteasome pathway targeting protein degradation ${ }^{75}$. Additionally, proinflammatory cytokines impede the function and expression of IGF- $1^{76}$, a local anabolic growth factor involved in protein anabolism. Collectively, these results suggest that proinflammatory cytokines can interfere with skeletal muscle recovery following exercise.

Nutrients can profoundly affect cytokine biology 73,77 . Previous research has shown that antioxidant supplementation can impact immune function in response to exercise by neutralizing $\operatorname{ROS}^{78-80}$. Other studies have supported the impact of antioxidant supplementation on immune parameters ${ }^{81,82}$. Further research indicates that supplementation with a combination of antioxidants attenuates exercise-induced inflammatory responses ${ }^{83,84}$. Similarly, supplementation of some ergogenic aids, such as creatine monohydrate and $\beta$-hydroxy- $\beta$-methylbutyrate, has demonstrated a reduction in proinflammatory cytokines post-exercise ${ }^{85-87}$.

The ingredient administered in this study was freezedried Se, Tetraselmis chuii. This microalgae has highly active antioxidant enzymes, namely superoxide dismutase (SOD), which catalyzes the conversion of superoxide into molecular oxygen, thereby reducing the risk of oxidative cell damage ${ }^{24}$. The ingredient was also found to upregulate glutathione peroxidase and catalase enzymes in human skeletal muscle myoblasts in vitro ${ }^{24}$. Studies have shown that exercise-induced muscle damage can be reduced with acute $^{88,89}$ and chronic ${ }^{90-92}$ antioxidant supplementation, and consequently, attenuate the inflammatory cytokine response $^{83}$. An independent analysis of the present ingredient demonstrated high antioxidant capacity via high concentrations of SOD $(38,000$ IU per gram) with robust corresponding ORAC values for the corresponding anion of the enzymes. These properties led us to explore the impact of the ingredient on muscle oxidative stress and the ensuing 
proinflammatory cytokine response. We observed a reduction in muscle MDA, an indicator of oxidative stress, and a reduction in the proinflammatory cytokine response of IL$1 \beta$ and TNF- $\alpha$. These proinflammatory markers contribute to muscle catabolism and may affect contractile properties and diminish the function of the neuromuscular junction ${ }^{93,94}$. Consequently, it is plausible that mitigating proinflammatory cytokines could concomitantly improve the function of the neuromuscular joint and subsequently improve the functional capacity of the musculature. This cascade of events has been previously proposed ${ }^{95}$.

There are some noteworthy limitations to this study. Participants were instructed to maintain their typical eating habits (e.g., eat the same number of meals with the same meal schedule) and avoid drastic changes in diet types. However, dietary intake was not tracked; therefore, nutrition data could not be provided. Additionally, other habits potentially affecting exercise recovery, such as sleep and non-exercise-related activity outside of the laboratory, were not monitored. Next, in the human model, we did not measure common hormonal or oxidative stress biomarkers used in previous research to evaluate exercise-related stress or recovery ${ }^{9,96-98}$. Lastly, the training volume was tracked only on the final training session (day 5) by counting completed repetitions in a lower-body muscle failure protocol. However, considering that both groups had similar force generation capacity at Pre and accumulated similar volume on day 5, it is conceivable that a similar training status existed between groups that could prompt parallel volume loads for the entire protocol.

In the human trial, we can conclude that the exercise stimulus was effective at inducing high levels of muscle damage, as indicated by reductions in muscle force indices and induced immunosuppression. Supplementation with the microalgae Tetraselmis chuii improved short-term recovery, reduced functional muscle damage, and better preserved immune function during the fatiguing period. We have shown that microalgae supplementation can preserve immune function following intensive training, thus initiating a more favorable environment for recovery and adaptation in humans. Second, we present mechanistic data in a rat model supporting the role of microalgae in modulating the proinflammatory cytokine response and reducing oxidative stress during exercise training. These findings shed light on a plausible nutritional intervention provoking immunomodulatory effects that may be involved in enhancing exercise recovery following intense, fatiguing protocols.

\section{ACKNOWLEDGEMENTS}

This study was financially supported by Lonza Consumer Health Inc. S.D. and Z.S. were employed by Lonza Consumer Health Inc. Neither of these authors were involved in data collection, data curation, or formal analysis. All other authors have no competing interests to declare.

\section{REFERENCES}

1. Zaldivar F, Wang-Rodriguez J, Nemet D, Schwindt C, Galassetti P, Mills PJ et al. Constitutive pro- and anti-inflammatory cytokine and growth factor response to exercise in leukocytes. J Appl Physiol. 2006;100:1124-33.

2 Maclntyre DL, Sorichter S, Mair J, Berg A, McKenzie DC. Markers of inflammation and myofibrillar proteins following eccentric exercise in humans. Eur J Appl Physiol. 2001;84:180-6.

3 Peake J, Nosaka K, Suzuki K. Characterization of inflammatory responses to eccentric exercise in humans. Exerc Immunol Rev. 2005;11:64-85.

4 Moldoveanu Al, Shephard RJ, Shek PN. The Cytokine Response to Physical Activity and Training. Sports Med. 2001;31:115-44.

5 Dinarello CA. Proinflammatory Cytokines. CHEST. 2000;118:5038.

6 Allen J, Sun Y, Woods JA. Exercise and the Regulation of Inflammatory Responses. Prog Mol Biol Trans/ Sci. 2015;135:337-54.

7 Sen CK. Oxidants and antioxidants in exercise. J Appl Physiol. 1995;79:675-86.

8 Niess AM, Dickhuth HH, Northoff $H$, Fehrenbach E. Free radicals and oxidative stress in exercise--immunological aspects. Exerc Immunol Rev. 1999;5:22-56.

9 Margonis K, Fatouros IG, Jamurtas AZ, Nikolaidis MG, Douroudos I, Chatzinikolaou A et al. Oxidative stress biomarkers responses to physical overtraining: Implications for diagnosis. Free Radic Biol Med. 2007;43:901-10.

10 Tanskanen M, Atalay M, Uusitalo A. Altered oxidative stress in overtrained athletes. J Sports Sci. 2010;28:309-17.

11 Peake JM, Suzuki K, Coombes JS. The influence of antioxidant supplementation on markers of inflammation and the relationship to oxidative stress after exercise. J Nutr Biochem. 2007;18:35771.

$12 \mathrm{Li} \mathrm{JJ}$, Oberley LW. Overexpression of manganese-containing superoxide dismutase confers resistance to the cytotoxicity of tumor necrosis factor alpha and/or hyperthermia. Cancer Res. 1997:57:1991-8.

13 Gleeson M. Immune function in sport and exercise. J Appl Physiol. 2007;103:693-9.

14 Martin SA, Pence BD, Woods JA. Exercise and respiratory tract viral infections. Exerc Sport Sci Rev. 2009;37:157-64.

15 Fiore AE, Shay DK, Broder K, Iskander JK, Uyeki TM, Mootrey G, Bresee JS, Cox NJ. Centers for cisease control and prevention. Prevention and control of seasonal influenza with vaccines: recommendations of the advisory committee on immunization practices (ACIP), 2009. MMWR Recomm Rep. 2009;58:1-52. Erratum in MMWR Recomm Rep. 2009;58:896-7.

16 Mackinnon LT, Hooper S. Mucosal (secretory) immune system responses to exercise of varying intensity and during overtraining. Int J Sports Med. 1994;15 Suppl 3:S179-83.

17 Gleeson M, Pyne DB, Austin JP, Lynn Francis J, Clancy RL, McDonald WA et al. Epstein-Barr virus reactivation and upper-respiratory illness in elite swimmers. Med Sci Sports Exerc. 2002;34:411-7.

18 Fahlman MM, Engels H-J. Mucosal IgA and URTI in American college football players: a year longitudinal study. Med Sci Sports Exerc. 2005;37:374-80.

19 Kellmann M, Bertollo M, Bosquet L, Brink M, Coutts AJ, Duffield R 
et al. Recovery and Performance in Sport: Consensus Statement. Int J Sports Physiol Perform. 2018;13:240-5.

20 Alessio HM, Goldfarb AH, Cao G. Exercise-induced oxidative stress before and after vitamin $\mathrm{C}$ supplementation. Int J Sport Nutr. 1997;7:1-9.

21 Meydani M, Evans WJ, Handelman G, Biddle L, Fielding RA, Meydani SN et al. Protective effect of vitamin E on exercise-induced oxidative damage in young and older adults. Am J Physiol. 1993;264: R992-8.

22 Peternelj T-T, Coombes JS. Antioxidant supplementation during exercise training: beneficial or detrimental? Sports Med. 2011:41:1043-69.

23 McGinley C, Shafat A, Donnelly AE. Does Antioxidant Vitamin Supplementation Protect against Muscle Damage? Sports Med. 2009:39:1011-32.

24 Ramirez P, Torres S, Lama C, Mantecon L, Unamunzaga C, Infante $C$. TetraSOD activates the antioxidant response pathway in human cells: An in vitro approach. Afr J Biotechnol. 2020;19:36773.

25 Dekkers JC, van Doornen LJ, Kemper HC. The role of antioxidant vitamins and enzymes in the prevention of exercise-induced muscle damage. Sports Med. 1996;21:213-38.

26 Jakeman JR, Lambrick DM, Wooley B, Babraj JA, Faulkner JA. Effect of an acute dose of omega-3 fish oil following exercise-induced muscle damage. Eur J Appl Physiol. 2017;117:575-82.

27 Urso ML, Clarkson PM. Oxidative stress, exercise, and antioxidant supplementation. Toxicology. 2003;189:41-54.

28 Wilson J, Wilson S, Loenneke J, Wray M, Norton L, Campbell B et al. Effects of Amino Acids and their Metabolites on Aerobic and Anaerobic Sports. Strength Cond J. 2012;34:33-48.

29 Faul F, Erdfelder E, Lang A-G, Buchner A. G*Power 3: a flexible statistical power analysis program for the social, behavioral, and biomedical sciences. Behav Res Methods. 2007;39:175-91.

30 Sharp M, Sahin K, Stefan M, Orhan C, Gheith R, Reber D et al Phytoplankton Supplementation Lowers Muscle Damage and Sustains Performance across Repeated Exercise Bouts in Humans and Improves Antioxidant Capacity in a Mechanistic Animal. Nutrients. 2020;12:1990.

31 Raeder C, Wiewelhove T, Westphal-Martinez MP, Fernandez-Fernandez J, de Paula Simola RA, Kellmann M et al. Neuromuscular Fatigue and Physiological Responses After Five Dynamic Squat Exercise Protocols. J Strength Cond Res. 2016:30:953-65.

32 Ahtiainen JP, Pakarinen A, Kraemer WJ, Häkkinen K. Acute hormonal and neuromuscular responses and recovery to forced vs maximum repetitions multiple resistance exercises. Int J Sports Med. 2003;24:410-8.

33 Benson C, Docherty D, Brandenburg J. Acute neuromuscular responses to resistance training performed at different loads. J Sci Med Sport. 2006:9:135-42.

34 Mazzetti SA, Kraemer WJ, Volek JS, Duncan ND, Ratamess NA, Gómez AL et al. The influence of direct supervision of resistance training on strength performance. Med Sci Sports Exerc. 2000:32:1175-84.

35 Garnacho-Castaño MV, López-Lastra S, Maté-Muñoz JL. Reliability and validity assessment of a linear position transducer. $J$ Sports Sci Med. 2015;14:128-36.

36 Jehanli A, Dunbar J, Skelhorn S. Development and validation of an oral fluid collection device and its use in the immunoassay of salivary steroids and immunoglobulins in sports persons. Proc 10th Symp Intl Soc Ex Imunol. 2011

37 Liu Y-F, Chen H, Yu L, Kuo Y-M, Wu F-S, Chuang J-I et al. Upregulation of hippocampal TrkB and synaptotagmin is involved in treadmill exercise-enhanced aversive memory in mice. Neurobiol Learn Mem. 2008;90:81-9.

38 Tan SH, Tan SB. The Correct Interpretation of Confidence Intervals. Proc Singap Healthc. 2010;19:276-8.

39 Morgan DL, Allen DG. Early events in stretch-induced muscle damage. J Appl Physiol. 1999;87:2007-15.

40 Proske U, Morgan DL. Muscle damage from eccentric exercise: mechanism, mechanical signs, adaptation and clinical applications. J Physiol. 2001;537:333-45.

41 Philippou A, Maridaki M, Bogdanis GC. Angle-specific impairment of elbow flexors strength after isometric exercise at long muscle length. J Sports Sci. 2003;21:859-65.

42 Philippou A, Bogdanis GC, Nevill AM, Maridaki M. Changes in the angle-force curve of human elbow flexors following eccentric and isometric exercise. Eur J Appl Physiol. 2004;93:237-44.

43 Jones DA, Newham DJ, Round JM, Tolfree SE. Experimental human muscle damage: morphological changes in relation to other indices of damage. J Physiol. 1986;375:435-48.

44 Sorichter S, Puschendorf B, Mair J. Skeletal muscle injury induced by eccentric muscle action: muscle proteins as markers of muscle fiber injury. Exerc Immunol Rev. 1999;5: 5-21.

45 Philippou A, Bogdanis G, Maridaki M, Halapas A, Sourla A, Koutsilieris M. Systemic cytokine response following exercise-induced muscle damage in humans. Clin Chem Lab Med. 2009;47:777-82.

46 Tidball JG. Inflammatory processes in muscle injury and repair. Am J Physiol Regul Integr Comp Physiol. 2005;288:R345-53.

47 Peñailillo L, Blazevich A, Numazawa H, Nosaka K. Rate of force development as a measure of muscle damage. Scand J Med Sci Sports. 2015;25:417-27.

48 Maffiuletti NA, Aagaard P, Blazevich AJ, Folland J, Tillin N, Duchateau J. Rate of force development: physiological and methodological considerations. Eur J Appl Physiol. 2016;116:1091-116.

49 Zając A, Chalimoniuk M, Maszczyk A, Gołaś A, Lngfort J. Central and Peripheral Fatigue During Resistance Exercise - A Critical Review. J Hum Kinet. 2015;49:159-69.

50 Löscher WN, Nordlund MM. Central fatigue and motor cortical excitability during repeated shortening and lengthening actions. Muscle Nerve. 2002;25:864-72.

51 Amann M, Sidhu SK, Weavil JC, Mangum TS, Venturelli M. Autonomic responses to exercise: group III/IV muscle afferents and fatigue. Auton Neurosci Basic Clin. 2015;188:19-23.

52 Meeusen R, Watson P, Hasegawa H, Roelands B, Piacentini MF. Central fatigue: the serotonin hypothesis and beyond. Sports Med. 2006;36:881-909.

53 Fragala MS, Kraemer WJ, Denegar CR, Maresh CM, Mastro AM, Volek JS. Neuroendocrine-immune interactions and responses to exercise. Sports Med. 2011;41:621-39.

54 Roberts JA. Viral illnesses and sports performance. Sports Med. 1986:3:298-303.

55 Heath GW, Ford ES, Craven TE, Macera CA, Jackson KL, Pate RR. Exercise and the incidence of upper respiratory tract infections. Med Sci Sports Exerc. 1991;23:152-7.

56 Matthews CE, Ockene IS, Freedson PS, Rosal MC, Merriam 
PA, Hebert JR. Moderate to vigorous physical activity and risk of upper-respiratory tract infection. Med Sci Sports Exerc. 2002;34:1242-8.

57 Nieman DC, Johanssen LM, Lee JW, Arabatzis K. Infectious episodes in runners before and after the Los Angeles Marathon. $J$ Sports Med Phys Fitness. 1990;30:316-28.

58 Friman G, Ilbäck NG. Acute infection: metabolic responses, effects on performance, interaction with exercise, and myocarditis. Int J Sports Med. 1998;19 Suppl 3:S172-82.

59 Kreher JB. Diagnosis and prevention of overtraining syndrome: an opinion on education strategies. Open Access J Sports Med. 2016;7:115-22.

60 Gleeson M, McDonald WA, Cripps AW, Pyne DB, Clancy RL, Fricker PA. The effect on immunity of long-term intensive training in elite swimmers. Clin Exp Immunol. 1995;102:210-6.

61 Niess AM, Simon P. Response and adaptation of skeletal muscle to exercise--the role of reactive oxygen species. Front Biosci J Virtual Libr. 2007;12:4826-38.

62 Pattwell DM, Patwell DM, McArdle A, Morgan JE, Patridge TA, Jackson MJ. Release of reactive oxygen and nitrogen species from contracting skeletal muscle cells. Free Radic Biol Med. 2004;37:1064-72.

63 Gissel H. The role of Ca2+ in muscle cell damage. Ann N Y Acad Sci. 2005;1066:166-80.

64 Kozakowska M, Pietraszek-Gremplewicz K, Jozkowicz A, Dulak $\mathrm{J}$. The role of oxidative stress in skeletal muscle injury and regeneration: focus on antioxidant enzymes. J Muscle Res Cell Motil. 2015;36:377-93.

65 Mason RP, Walter MF, Mason PE. Effect of oxidative stress on membrane structure: small-angle X-ray diffraction analysis. Free Radic Biol Med. 1997;23:419-25.

66 Tryfidou DV, McClean C, Nikolaidis MG, Davison GW. DNA Damage Following Acute Aerobic Exercise: A Systematic Review and Meta-analysis. Sports Med. 2020;50:103-27.

67 Alessio HM. Exercise-induced oxidative stress. Med Sci Sports Exerc. 1993;25:218-24.

68 Sjödin B, Hellsten Westing Y, Apple FS. Biochemical mechanisms for oxygen free radical formation during exercise. Sports Med. 1990;10:236-54.

69 Chaudhri G, Clark IA. Reactive oxygen species facilitate the in vitro and in vivo lipopolysaccharide-induced release of tumor necrosis factor. J Immunol. 1989; 143: 1290-4.

70 Schreck R, Rieber P, Baeuerle PA. Reactive oxygen intermediates as apparently widely used messengers in the activation of the NF-kappa B transcription factor and HIV-1. EMBO J. 1991;10: 2247-58.

71 Pfizenmaier K, Scheurich P, Himmler A, Schütze S, Krönke M. Tumor Necrosis Factor and Lymphotoxin-Induced Signal Pathways. In Freund M., Link H., Schmidt R.E., Welte K. (eds), Cytokines in Hemopoiesis, Oncology, and AIDS II. Springer-Verlag, Berlin Heidelberg. Berlin, Germany. 1992;233-8.

72 DeForge LE, Fantone JC, Kenney JS, Remick DG. Oxygen radical scavengers selectively inhibit interleukin 8 production in human whole blood. J Clin Invest. 1992;90:2123-9.

73 Grimble RF. Malnutrition and the immune response. 2. Impact of nutrients on cytokine biology in infection. Trans $R$ Soc Trop Med Hyg. 1994;88:615-9.

74 Dehoux M, Gobier C, Lause P, Bertrand L, Ketelslegers J-M,
Thissen J-P. IGF-I does not prevent myotube atrophy caused by proinflammatory cytokines despite activation of Akt/Foxo and GSK-3beta pathways and inhibition of atrogin-1 mRNA. Am J Physiol Endocrinol Metab. 2007;292:145-50.

75 Bistrian BR, Schwartz J, Istfan NW. Cytokines, muscle proteolysis, and the catabolic response to infection and inflammation. Proc Soc Exp Biol Med. 1992;200:220-3.

76 Grounds MD, Radley HG, Gebski BL, Bogoyevitch MA, Shavlakadze T. Implications of cross-talk between tumour necrosis factor and insulin-like growth factor-1 signalling in skeletal muscle. Clin Exp Pharmacol Physiol. 2008;35:846-51.

77 Grimble RF. Nutritional modulation of cytokine biology. Nutrition. 1998;14:634-40.

78 Babior BM. Oxidants from phagocytes: agents of defense and destruction. Blood. 1984;64:95966.

79 Hemilä H. Vitamin C and the common cold. Br J Nutr. 1992;67:316

80 Ashton T, Young IS, Peters JR, Jones E, Jackson SK, Davies B, Rowlands CC. Electron spin resonance spectroscopy, exercise, and oxidative stress: an ascorbic acid intervention study. J Appl Physiol. 1999; 87:2032-6.

81 Nieman DC, Henson DA, Butterworth DE, Warren BJ, Davis JM, Fagoaga OR, Nehlsen Cannarella SL. Vitamin C supplementation does not alter the immune response to 2.5 hours of running. Int $\mathrm{J}$ Sport Nutr. 1997;7:173-84.

82 Petersen EW, Ostrowski K, Ibfelt T, Richelle M, Offord E, Halkjaer-Kristensen J, Pedersen BK. Effect of vitamin supplementation on cytokine response and on muscle damage after strenuous exercise. Am J Physiol-Cell Physiol. 2001;280:1570-5

83 Vassilakopoulos $\mathrm{T}$, Karatza M-H, Katsaounou P, Kollintza A, Zakynthinos S, Roussos C. Antioxidants attenuate the plasma cytokine response to exercise in humans. J Appl Physiol. 2003:94:1025-32.

84 Fischer CP, Hiscock NJ, Penkowa M, Basu S, Vessby B, Kallner A, Sjöberg LB, Pedersen BK. Supplementation with vitamins $C$ and $E$ inhibits the release of interleukin- 6 from contracting human skeletal muscle. J Physiol. 2004; 558:633-45.

85 Bassit RA, Curi R, Costa Rosa LFBP. Creatine supplementation reduces plasma levels of pro-inflammatory cytokines and PGE2 after a half-ironman competition. Amino Acids. 2008;35:425-31.

86 Kraemer WJ, Hatfield DL, Comstock BA, Fragala MS, Davitt PM, Cortis C, Wilson JM, Lee EC, Newton RU, Dunn-Lewis C, Häkkinen K, Szivak TK, Hooper DR, Flanagan SD, Looney DP, White MT, Volek JS, Maresh CM. Influence of HMB supplementation and resistance training on cytokine responses to resistance exercise. J Am Coll Nutr. 2014;33:247-55.

87 Townsend JR, Fragala MS, Jajtner AR, Gonzalez AM, Wells AJ, Mangine GT, Robinson EH 4th, McCormack WP, Beyer KS, Pruna GJ, Boone CH, Scanlon TM, Bohner JD, Stout JR, Hoffman JR. $\beta$-Hydroxy- $\beta$-methylbutyrate (HMB)-free acid attenuates circulating TNF- $\alpha$ and TNFR1 expression postresistance exercise. J Appl Physiol. 2013;115:1173-82.

88 Santos SA, Silva ET, Caris AV, Lira FS, Tufik S, Dos Santos RVT. Vitamin $E$ supplementation inhibits muscle damage and inflammation after moderate exercise in hypoxia. J Hum Nutr Diet Off $J$ Br Diet Assoc. 2016;29:516-22.

89 Nie J, Lin $\mathrm{H}$. Effects of vitamin $\mathrm{C}$ supplementation on recovery from eccentric exercise-induced muscle soreness and damage in 
junior athletes. J Exerc Sci Fit. 2004;2:94-8.

90 McBride JM, Kraemer WJ, Triplett-McBride T, Sebastianelli W. Effect of resistance exercise on free radical production. Med Sci Sports Exerc. 1998;30:67-72.

91 Rokitzki L, Logemann E, Sagredos AN, Murphy M, Wetzel-Roth W, Keul J. Lipid peroxidation and antioxidative vitamins under extreme endurance stress. Acta Physiol Scand. 1994;151:149-58.

92 Bryer SC, Goldfarb AH. Effect of high dose vitamin C supplementation on muscle soreness, damage, function, and oxidative stress to eccentric exercise. Int J Sport Nutr Exerc Metab. 2006;16:270-80.

93 Reid MB, Li Y-P. Tumor necrosis factor-a and muscle wasting: a cellular perspective. Respir Res. 2001;2:269-72.

94 Gonzalez-Freire M, de Cabo R, Studenski SA, Ferrucci L. The neuromuscular junction: aging at the crossroad between nerves and muscle. Front Aging Neurosci. 2014;6.

95 Tomeleri CM, Ribeiro AS, Souza MF, Schiavoni D, Schoenfeld BJ Venturini D, Barbosa DS, Landucci K, Sardinha LB, Cyrino ES Resistance training improves inflammatory level, lipid and glycemic profiles in obese older women: a randomized controlled trial. Exp Gerontol. 2016;84:80-7.

96 Fry AC, Kraemer WJ, Stone MH, Warren BJ, Kearney JT, Maresh $\mathrm{CM}$, Weseman CA, Fleck SJ. Endocrine and performance responses to high volume training and amino acid supplementation in elite junior weightlifters. Int J Sport Nutr. 1993;3:306-22.

97 Häkkinen K, Keskinen KL, Alén M, Komi PV, Kauhanen H. Serum hormone concentrations during prolonged training in elite endurance-trained and strength-trained athletes. Eur J Appl Physiol. 1989:59:233-8

98 Hayes LD, Grace FM, Baker JS, Sculthorpe N. Exercise-induced responses in salivary testosterone, cortisol, and their ratios in men: a meta-analysis. Sports Med. 2015;45:713-26. 